\title{
Significance of UV-C Hormesis and Its Relation to Some Phytochemicals in Ripening and Senescence Process
}

\author{
Maharaj Rohanie ${ }^{1}$ and Mohammed Ayoub 2 \\ 1 University of Trinidad and Tobago, Piarco \\ ${ }^{2}$ National Agricultural Marketing Development Corporation, Piarco
}

Trinidad

\section{Introduction}

Recently, the Food Agricultural Organization of the United Nations (FAO, 2009) predicted that the world population would top eight billion by the year 2030. Therefore, the demand for food would increase dramatically. Fruits and vegetables will play an important role in providing essential vitamins, minerals and dietary fibre to the world feeding populations in both developed and developing countries. Organizations such as FAO have also recommended increasing fruits and vegetables consumption to decrease the risk of cardiovascular diseases and cancer. Moreover, as far as health is concerned, quality and safety in foods are important criteria demanded by consumers.

Fruits and vegetables are perishable products with active metabolism during the postharvest period and the major limitations in their storability are senescence, fungal infection and water loss (Brady, 1987). Such crops are classified as being either climacteric or non climacteric based on their respiratory and ethylene production patterns during storage life. Climacteric fruits show a marked increase in respiration and increase ethylene $\left(\mathrm{C}_{2} \mathrm{H}_{4}\right)$ production during their ripening whereas non-climacteric fruit and vegetables complete ripening without increases in respiration and independent of increase $\mathrm{C}_{2} \mathrm{H}_{4}$ production (Wills et al., 1981). There is extensive experimental evidence indicating that the increase in $\mathrm{C}_{2} \mathrm{H}_{4}$ production is linked to the main biochemical and physiological changes that occur during ripening, leading to a loss in skin resistance, increased water loss, senescence and ultimately postharvest diseases. Examples of postharvest diseases arising from quiescent infections include anthracnose of various tropical fruit caused by Colletotrichum spp. and grey mould of strawberry caused by Botrytis cinerea. Preservation of these crops in as fresh as possible state, with minimum loss in quality during handling and storage, will primarily involve retardation of the physiological and biochemical changes associated with ripening and senescence (Wills et al., 1981).

Methods aimed at improving postharvest shelf-life and quality particularly for tropical climacteric horticultural commodities should be addressed. Some of the current methods employed to delay ripening and senescence and increase shelf-life of crops include:-low temperature storage combined with high humidity, as well as the use of modified and 
controlled atmospheres, various coatings and waxes (Yahia, 1998). Certain fungicides have also been employed to control postharvest diseases and improve quality of horticultural crops but these have been met with resistance from consumers who want healthy, safe and nutritious foods. The benefits of these techniques have been reported for a wide myriad of fruits and vegetables however, all these techniques must be applied with refrigeration, as temperature is the dominant factor influencing all plant processes (Pearce, 1999). Developing newer techniques and technologies in order to improve postharvest longevity of horticultural crops has always been a challenge to researchers. With application of adequate technology to prevent deterioration after harvest and considering the biochemical characteristics of the produce, postharvest losses can be significantly reduced.

\subsection{Phytochemicals in horticultural crops}

Phytochemicals are plant components that have gained considerable attention as photoprotective agents in providing certain human health benefits and have been the subject of numerous investigations (Shahidi et al., 2011; Butt \& Sultan, 2011; Heber, 2004; RamanaLuximon et al., 2003). Phytochemicals belong to several classes that include polyphenols, flavonoids, isoflavonoids, phytoalexins, phenols, anthocyanidins and carotenoids. They are widely distributed with different structures at the tissue, cellular and sub-cellular levels (Shahidi \& Naczk, 2004). Frequent consumption of fruits is associated with health promoting effects of plant phytochemicals in particular their antioxidant properties. Phytochemicals may work in promoting human health and disease prevention in different ways such as: by stimulating the immune response, by inducing gene suppression, by blocking oxidative damage to DNA, by detoxifying carcinogens and by initiating selected signaling pathways or by other mechanisms (Adhami et al., 2008; Schreiner \& Huyskens-Keil, 2006).

Researchers have been able to isolate numerous bioactive phytochemicals which are well known for their powerful antioxidant and free radical scavenging potential (Jergensen et al., 1999). Moreover, specific postharvest elicitor treatments, such as low or high temperature treatments, ultraviolet and gamma irradiation, altered gas composition or application of signaling molecules may further enhance phytochemical content (Schreiner \& HuyskensKeil, 2006). Their possible impact on maintaining human health and prevention of diseases continue to be an active research (Ramana-Luximon et al., 2003).

\section{UV-C hormesis}

There is now considerable literature on the use of controlled abiotic stresses to delay postharvest senescence of horticultural crops. A treatment that could activate the mechanisms of the plant against the toll of senescence can be a useful method in the preservation of fresh tropical crops. One example of such technology, which is not expensive, simple and uses non-ionizing energy is ultraviolet (UV) radiation. UV-radiation has been classified as UV-C (200-280 nm), UV-B (280-320 nm) and UV-A (320-400 nm). Each band can induce significantly different biological effects in crops (Shama, 2007; Bintsis et al., 2000). UV-C wavelengths are absorbed in the stratosphere and are removed from the light reaching the earth's surface so long as there is ozone present. Most of the information on the biological effects of UV-radiation is derived from experiments using artificial UV-C, particularly $254 \mathrm{~nm}$ radiation (Bintsis et al., 2000). 
Exposure to UV-radiation is well known to have deleterious effects of plant tissues. However, a biphasic dose response relationship in which low irradiation doses cause a stimulatory effect of beneficial responses while high doses cause detrimental (toxic) effects on plant tissues is termed Hormesis (Arul et al., 2001; Calabrese et al., 1987).

UV-C radiation is mainly used as a surface treatment because it penetrates only 5-30 microns of the tissue. It has been extensively used in the disinfection of equipment, glassware and air by food and medical industries for many years. Low pressure mercury $(\mathrm{Hg})$ lamps are often called "germicidal" because most of their total radiation energy is at a wavelength of $253.7 \mathrm{~nm}$, which is near the maximum for germicidal effectiveness, hence its usefulness in the control of microorganisms (Kowalski, 2009). While the application of hormesis is used in the context of this chapter on the benefits to plant tissues, hormic responses have also been shown in bacteria, fungi, animals and humans (Shama, 2007).

UV-light is absorbed by certain chemical groupings of molecules (chromophores) such as conjugated double bonds and results in photochemical reactions. The chromophores eg. nucleic acids, proteins, indoleacetic acid, flavoproteins and phytochrome have key roles in plant cell function and structure and any alterations of these compounds due to UV might be expected to cause physiological alterations in plants (Caldwell, 1981). DNA is one of the most important target molecules for photobiological effects. UV-C light can be (1) directly absorbed by DNA and (2) involved in photooxidation in plants via free radical production. Thus damage to plants as a result of UV-C can be classified into two categories: damage to DNA and damage to physiological processes (Stapleton, 1992). The intrusion of activated oxygen species into biological systems as well as changes to DNA results ultimately in deleterious effects for example, too much UV damages DNA in soyabeans, destroys their chlorophyll and disrupts photosynthesis which leads to poor yields (Vikhanski, 1989). However certain crops are resistant to such adverse effects by having DNA repair systems by gene activation and quenching systems which can undo the damage caused by UV-C.

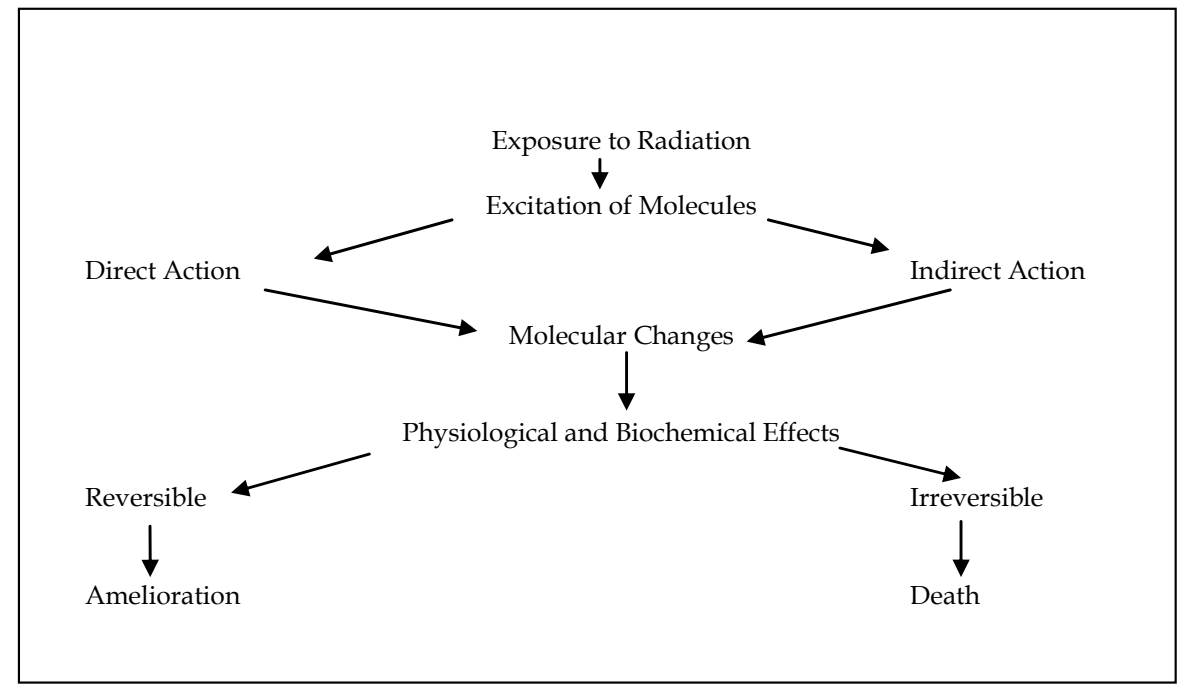

Fig. 1. Schematic representation of the photobiological effects of UV-C radiation in plants 


\subsection{Intense light pulses}

In response to consumer preferences for high quality foods that are as close as possible to fresh products, athermal technologies are being developed to obtain products with high levels of organoleptic and nutritional quality but free of any health risks. Intense pulsed light (IPL) is a novel technology that rapidly inactivates pathogenic and food spoilage microorganisms. It appears to constitute a good alternative or a complement to conventional thermal or chemical decontamination processes (Elmnasser et al., 2007). Intense pulsed light (IPL) decontaminates food surfaces by killing microorganisms using short time high frequency pulses of an intense broad spectrum, rich in UV-C light. Different mechanisms have been proposed to explain the lethal effect of ILP, all of them related with the UV part of the spectrum and with its photochemical and/or photothermal effect (Anderson et al., 2000).

The decontamination effect of pulsed light on minimally processed vegetables have been reported, with $\log$ reductions between 0.56 and 2.04 achieved with mesophilic aerobic microorganisms (Gómez-López et al., 2005). On the other hand, exposure of pea plants to short pulses of UV-C radiation for 10, 14 and 21 consecutive days did not cause noticeable activation of the major antioxidant enzymes in the youngest leaves suggesting a different defence system for these plants (Katerova, 2009).

\subsection{UV-C as an antimicrobial agent}

The benefits of UV-C as a germicidal agent has found practical applications in a broad range of antimicrobial applications including inhibiting microorganisms from the surface of food products, destruction of microorganisms in air and sterilization of liquids (Bintsis et al., 2000). UV-C radiation can inactivate the pathogens that may be present at the surface of fruit (Artes-Hernandez et al., 2009). Exposure of fruits and vegetables to UV-C light at around $254 \mathrm{~nm}$ has been evaluated as a possible alternative to chemical fungicides for the control of postharvest diseases, rather than ripening. This is principally because of (1) its germicidal properties, and (2) UV-C activates the mechanism of defence of crops against infection by the de novo synthesis of antimicrobial compounds such as phytoalexins. The ultraviolet light acts as an antimicrobial agent directly due to DNA damage (Rame et al., 1997) and indirectly due to the induction of resistance mechanisms in different fruit and vegetables against pathogens (Mercier et al., 2001; Nigro et al., 1998; Liu et al., 1993). Shama (2007), cites several references on the use of UV-C treatment and its beneficial effects on reducing and/or preventing postharvest storage rots including onions, potatoes, sweet potatoes, carrots, tomato, peaches, mangoes and strawberries. Several studies have been conducted on the use of UV-C radiation and its benefit as a non chemical decontamination agent for human pathogens that may be found in food (Bintsis et al., 2000). Grapes and strawberries were UV-C irradiated for $24-48 \mathrm{~h}$ before being inoculated with Botrytis cinerea and the results compared with those inoculated immediately before irradiation. The results showed a reduction in the postharvest incidence of disease after UV-C irradiation (Nigro et al., 1998, 2000).

It was reported that the use of two sided UV-C radiation at the appropriate dose was effective in reducing the natural microflora and extending the shelf-life of minimally processed "Red Oak Leaf" lettuce (Allende et al., 2006) and in control of rots in sweet potatoes at certain doses (Stevens et al., 1990). UV-C treatment has been reported to induce 
resistance against pathogens in a number of species (El Ghaouth et al., 2003; Nigro et al., 2000; Stevens et al., 1996). The activity of the phenylalanine ammonia lyase (PAL; EC 4.3.1.5) enzyme was induced by UV-C radiation in several fruits (Charles et al., 2009; Nigro et al., 2000). This UV treatment also enhanced the accumulation of flavonoids, phytoalexins, and phenolic antifungal compounds (Liu et al., 2009).

The production of phytoalexins, antimicrobial compounds produced by plants in response to infection or physiological stimuli such as UV-radiation, is believed to be an important defence mechanism. One proposed hypothesis on the mechanism of induction of phytoalexin supposes that in normal tissue the genes involved are repressed. Agents which induce phytoalexin production are thought to depress these genes or promote their transcription by causing a conformational change in DNA (Langcake \& Pryce, 1973).

UV-C light has been used in combination with other preservation techniques to preserve the quality of horticultural crops. Most of these studies showed the effectiveness of microbial reductions in fresh-cut fruits and vegetables by using chemical disinfection, low UV-C light doses (from 1 to $4 \mathrm{~kJ} / \mathrm{m}^{2}$ ) and storage under conventional MAP, without any detrimental effect on the organoleptic quality of the product. Additionally, UV-C light combined with other postharvest treatments such as mild thermal treatments and immersion in water at elevated temperatures showed improvements in keeping quality and reducing incidence of storage disease in various horticultural crops (Allende et al., 2006). The beneficial effects of a heatshock treatment to reduce browning in fresh-cut lettuce (e.g. $90 \mathrm{~s}$ at $45{ }^{\circ} \mathrm{C}$ ) was due to the redirecting of protein synthesis away from the production of wound induced enzymes of phenolic metabolism, and toward the production of innocuous heat shock proteins (Saltveit, 2000 as cited in Allende et al., 2006). The efficacy of heat treatments and UV-C light for controlling postharvest decay of strawberries and sweet cherries were tested. In most of the cases, fungal inactivation was achieved for the treatments with the highest UV-C dose $\left(10 \mathrm{~kJ} / \mathrm{m}^{2}\right)$ combined with a long thermal treatment $\left(15 \mathrm{~min}\right.$ at $\left.45^{\circ} \mathrm{C}\right)$. The sequence of the treatments seemed to have an influence on microbial inactivation for strawberries. The fungal inactivation was greater when the ultraviolet treatment preceded the thermal treatment. The possibility of lowering the intensity of the heat treatment when preceded by an ultraviolet illumination resulted in a decrease of fruit damage caused by heating. Since less intense thermal conditions can be used, visual damage to the strawberries was also reduced (Marquenie et al., 2002).

\subsection{UV-C and its role in plant tissue/organ senescence}

One of the major factors in the process of plant tissue/organ senescence is free radical damage. As a result of oxidation inherent in aerobic respiration, free radicals are formed and their targets may be cell membranes, nucleic acids, enzymes and cell walls resulting in an acceleration of senescence and tissue softening (Brady, 1987). These oxidation stresses become severe with the physiological age of the tissue and it responds by generating an array of detoxifying mechanisms (antioxidants and enzymes) against free radical attack. It is documented that short wavelength radiation exerts two pronounced effects on plant metabolism viz: at low intensities, it may give rise to an enhancement of secondary stress metabolites which can protect the plant from free radical damage, while at high intensities, it can cause an inhibition of these substances often leading to detrimental effects on the plant (Kowalski, 2009). Certain plants have repair mechanisms which involve the production of 
secondary stress metabolites for example, antioxidant compounds such as carotenoids, phenols, flavonoids, and polyamines. The enzyme superoxide dismutase (SOD) is postulated to ameliorate the toxic effects of superoxide and this enzyme is ubiquitously present in aerobic organisms (Cunningham et al., 1985). These compounds, usually present in the plant are generally activated following stress when produced in sufficient abundance in pre-climacteric crops can counteract the effect of DNA and free radical damage (which becomes important with age) and stimulate increase longevity of harvested crops. By stimulating the natural defences of the crop against adverse stresses, one can improve the storability of such commodities. The UV doses reported to achieve beneficial effects in fruits and vegetables range from $0.5 \mathrm{~kJ} / \mathrm{m}^{2}$ for strawberries to $9.0 \mathrm{~kJ} / \mathrm{m}^{2}$ for oranges (Shama \& Alderson, 2005). UV-C has also been documented to primarily control ripening and senescence in climacteric fruits (Maharaj et al., 2010; Hemmaty et al., 2006). On the other hand, prolonged exposure to UV irradiation has been found to accelerate ripening and senescence probably as a result of free radicals generated (Liu et al., 1993). Hyper UV-C doses have resulted in undesirable changes in skin colour, premature ripening, drying and infection in several crops as reported by Shama \& Alderson (2005). Thus low levels or hormic doses of UV-C radiation can be an adjunct to refrigeration for preservation of horticultural crops. Effectiveness of UV-C treatments varies with plant species, stage of maturity, irradiation dose and duration.

\section{Phytochemicals and UV-C hormesis}

The impact of UV-C hormesis on fresh fruits and vegetables has been the subject of numerous studies over the last few years (Shama, 2007). Fruits contain a huge diversity of phytochemicals (antioxidant compounds). Of these, phenolics and carotenoids have been shown to protect the cellular systems from oxidative damage induced by free radicals. Promising results have been shown with abiotic stress treatment in positively impacting on phytochemicals, either by preserving its content in fruits and vegetables or increasing its contents following treatment. A number of factors affect the efficacy of treatment in maintaining or increasing photochemical content including: the type of horticultural product, the length of exposure and the class of phytochemicals. Non-enzymatic compounds consisting of lipid soluble membrane associated antioxidant ( $\alpha$-tocopherol, $\beta$ carotene) and water soluble reductants (glutathione, ascorbate, phenolics) and enzymatic antioxidants (SOD, catalase, peroxidases) are induced in response to oxidative stress (Jaleel et al., 2009). Changes in levels of polyamines have been linked to senescence suggesting that lowering of polyamine concentration is a step in triggering senescence or that exogenous application of polyamines could inhibit senescence (Shama \& Alderson, 2005). The latter may be due to possible inhibition of ethylene synthesis and to stabilization and protection of membranes by associating with negatively charged phospholipids (Galston \& Kaur-Sawhney, 1990).

\subsection{Antioxidants: Carotenoids, lycopene and ascorbic acid}

Colour development involves a decrease in chlorophyll pigments with a concomitant increase in pigments (e.g. carotenoids) and is a characteristic of many plant tissues during both ripening and senescence (Gong \& Mattheis, 2003). Tomato fruit are a rich source of carotenoids, especially lycopene and $\beta$-carotene. UV-C has been shown to retard colour 
development, loss of chlorophyll and the development of lycopene which makes up the bulk of the carotenoid pigments in ripe tomato. Figure 2 illustrates the changes in lycopene content with storage time for both UV-treated and untreated tomato fruit stored under refrigeration. Lycopene is the major carotenoid in tomato accounting for more than $80 \%$ of the total carotenoids present in a fully ripe tomato fruit. The chloroplast seems to be one of the target sites for UV action and this offers evidence for reduction in the level of lycopene in irradiated tomatoes in comparison to the control fruits (Maharaj et al., 1999). However, production of total carotenoid pigments in tomato, were found to be higher in UV-treated fruits compared to the untreated ones. Carotenoids may be considered as an antioxidative phytochemical to counteract free radical damage with associated photosensitized reactions (Maharaj et al., 2010).

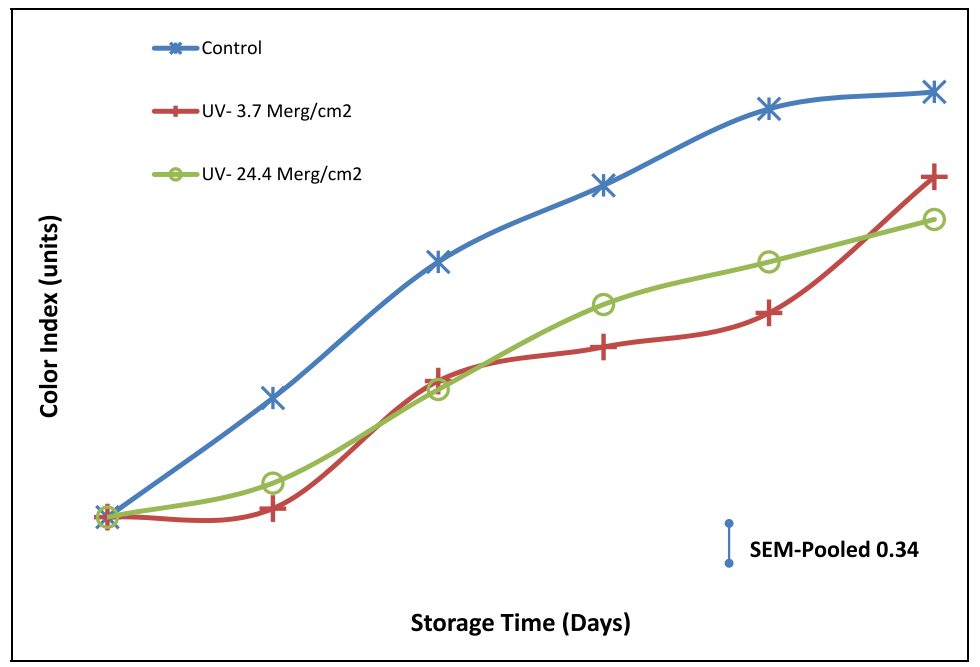

Fig. 2. Colour rating values $(1=$ mature green, $6=$ red $)$ of control and UV-C irradiated tomato stored at $16^{\circ} \mathrm{C}$. Mean for $n=4$ (with permission Maharaj et al., 2010).

The impact of UV-C radiation on senescence of broccoli florets were investigated (Costa et al., 2006). One of the key symptoms of quality loss in broccoli is the loss of green colour of the sepals due to chlorophyll degradation. Apart from loss of green colour, lipid peroxidation, loss of antioxidant capacity, reduced nutritional value and increased tissue degradation are also well associated with quality loss in broccoli. Costa et al. (2006) subjected broccoli florets to four different UV-C dosages: 4, 7, 10 and $14 \mathrm{~kJ} \mathrm{m-2}$ as well as an untreated control. All samples were stored at $20^{\circ} \mathrm{C}$ and evaluated after a six day storage period. The findings indicated that total chlorophyll loss was significantly higher in florets that were not radiated as compared to radiated florets having a mean chlorophyll content that was $53 \%$ higher than the control. UV-C seemed to have had a positive impact in reducing the degradation of both chlorophyll-a and -b. It appears from the findings that UV$\mathrm{C}$ treatment reduces the activity of chlorophyllase thus maintaining a greener colour than the control. Untreated florets had much higher chlorophyllase activity than UV-C treated florets. Pheophytin a by-product of chlorophyll degradation was also lower in UV-C irradiated broccoli with the exception of the highest $(14 \mathrm{~kJ} \mathrm{~m}-2)$ dose where higher levels of 
pheophytin were detected. They suggested that at high UV-C dosage, the release of magnesium ions may be in part responsible for this observation. In Shitake mushrooms, treatment with UV-C radiation had higher level of flavonoids and ascorbic acid as well as reducing free radical scavenging potential and decreased peroxide (Jiang et al., 2010). Antioxidant enzyme activity of phenylalanine ammonia lyase (PAL), $\beta-1,3$-glucanase, superoxide dismustase, catalase and gluthione reductase were induced to high levels by UV-C treated Yali pears (Li et al., 2010).

Vitamin C content is considered to be a quality index for fruits and vegetables occurs as Lascorbic acid and dehydroascorbic acid. Ascorbate is an electron donor and this property explains its function as an antioxidant or reducing agent. González-Aguilar et al. (2007) reported a reduction in total ascorbic acid content of UV-C irradiated fresh-cut mango fruits due to the oxidation of ascorbic acid by effect of the increment in UV-C exposure time.

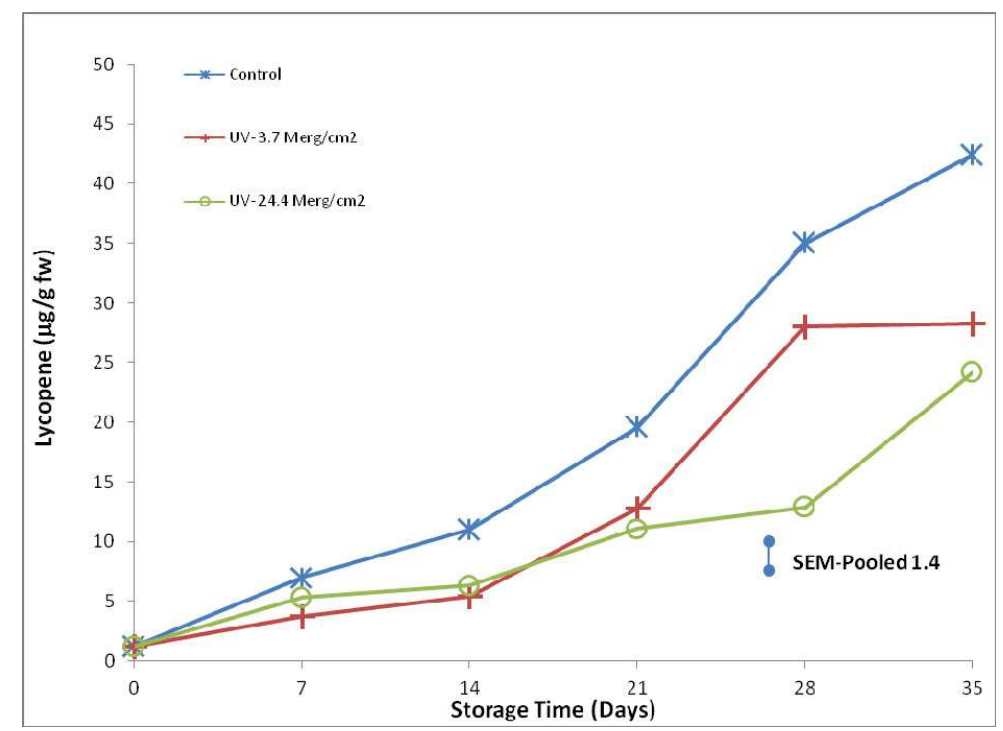

Fig. 3. Lycopene content of control and UV-C irradiated tomato stored at $16^{\circ} \mathrm{C}$. Mean for $n=4$ (with permission Maharaj et al., 2010).

\subsection{Phenolic compounds}

The largest category of phytochemicals and most widely distributed in the plant kingdom are the phenolics. Bioactive phenolic compounds are plant secondary metabolites that are biosynthesized through the shikimic acid pathway (Tomás-Barberán \& Espín, 2001). Phenolic compounds embrace a considerable range of substances which possess an aromatic ring bearing one or more hydroxyl groups. They may be classified into different groups as a function of the number of phenol rings that they contain and of the structural elements that bind these rings to each other. They exist in higher plants in many different forms including hydroxybenzoic derivatives, cinnamates, flavonoids (flavonols, flavones, flavanols, flavanones, isoflavones, proanthocyanidins), lignans, stilbenes, and which affect the quality characteristics of plants such as appearance, flavour and health-promoting properties. Plant 
phenolics are multifunctional and can act as reducing agents, metal chelators and singlet oxygen quenchers. Besides their role as antioxidants, phenolic compounds also possess antimicrobial properties and are involved in disease resistance by contributing to the healing of wounds by lignification of cell walls around wounded sites (Shahidi et al., 2011; Shahidi \& Naczk, 2004; Tomás-Barberán \& Espín, 2001). In addition, phenolics serve as substrates for browning reactions. The synthesis of certain phenols such as:- phytoalexins and lignins, that are all associated with local resistance processes, involves phenylalanine ammonia-lyase as a key step in the shikimic acid pathway (Shama \& Alderson, 2005). The three amino acids phenylaline, tyrosine and tryptophan are the primary metabolites which serve as precursors for many secondary products. The enzymes phenylalanine ammonialyase (PAL; EC 4.3.1.5), polyphenol oxidases (PPO; EC 1.14.18.1) and peroxidises (POD; EC 1.11.1.7) are the main enzymes responsible for phenolic degradation that often leads to quality loss (Shahidi et al., 2011).

Light intensity and wavelength have an important effect on phenolic metabolism, as they affect flavonoid and anthocyanin biosynthesis. Some researchers point out that UVradiation results in the accumulation flavonoids as they act as protective filter against (excessive) radiation and which may be implicated in the resistance of fruit and vegetables to microorganisms and senescence (Li et al., 2010; González-Aguilar et al., 2007; Shama \& Alderson, 2005). Radiation is also known to cause depolymerisation of cell wall polysaccahrides resulting in higher extraction of phenols. UV irradiation during postharvest storage has been used to increase anthocyanin pigmentation in the skin of red apples, sweet cherries and strawberries leading to an increase in quality (Tomás-Barberán \& Espín, 2001). In the case of apples, this increase correlated with an increase in both PAL and chalcone isomerase activities (Kataoka et al., 2003). On the other hand, no effect of postharvest UV irradiation on fruit pigmentation was detected in other crops such as nectarines, strawberries, grapes and plums showing that this treatment is not always useful for this purpose. In fact, UV irradiation produced necrosis and other quality losses in such irradiated fruits and these browning symptoms were attributed to the induced increased POD activity (Tomás-Barberán \& Espín, 2001).

The effects of UV-C have also been investigated on fresh cut tropical fruits. Slices of bananas (cv. Pisang mas,) pineapple (cv. Honey pineapple) and Thai seedless guavas were irradiated with UV-C light and the results compared against untreated slices (control) (Alothman et al., 2009). In bananas and guava, exposure to UV-C radiation resulted in an increase in total phenols and flavonoids. In pineapples however, there was a significant increase in flavonoids but UV-C irradiation did not have any significant increase in total phenol content. In another study, mango slices were subjected to UV-C radiation at three different exposure times and its effect compared to untreated fruit slices (González-Aguilar et al., 2007). The study found that the length of exposure to radiation and storage time significantly affected phenols, flavonoids, $\beta$-Carotene and vitamin C. Fresh-Cut mango slices were radiated for 1, 3, 5 and 10 minutes or left untreated. After 3 days of storage, slices irradiated for 1, 3 and 5 minutes showed a sharp increase in total phenols followed by a plateau for the rest of the storage period. Mango fruit slices irradiated for 10 minutes, showed progressive increase in total phenols throughout the 15 day storage period. Slices used as control showed the smallest incremental increase after 3 days compared to all irradiated samples and also had a plateau for the rest of the 15 day storage period with the smallest quantities of total phenols. Flavonoid contents were also 
significantly affected by length of radiation exposure and storage time. Slices irradiated for 5 and 10 minutes showed a sharp continuous increase in flavonoids over the 15 day storage duration compared to those irradiated for shorter times (1 and 3 minutes), which also showed increased flavonoids but to a lesser extent than slices irradiated for longer times ( 5 and 10 minutes). Stimulation of flavonoid levels by UV-C radiation could be attributed to a defence mechanism in scavenging free radicals due to the reactivity of the hydroxyl groups. It has also been reported that UV light could be used to increase the content of health-promoting phenolics such as resveratrol in grapes and coumarins in grapefruit (Tomás-Barberán \& Espín, 2001). The increase in total phenols and flavonoids in these studies may be attributed to their antioxidant and antimicrobial roles.

\subsection{Polyamines}

Polyamines (PA) are polyfunctional components present in plant and animal cells and are defined as "small polycationic biogenic amines" (Nambeesan et al., 2008). Polyamines (PA) are fairly ubiquitous, but of rather low concentrations ranging from micromolar to millimolar in mature fruit tissues (Galston \& Kaur-Sawhney, 1990; Heby \& Persson, 1990). They are implicated in a variety of regulatory processes ranging from regulation of growth and cell division, regulating the activity of ribonucleotides and proteinase to inhibition of $\mathrm{C}_{2} \mathrm{H}_{4}$ production and senescence (An et al., 2004; Valero et al., 2002; Pandey et al., 2000; Galston \& Kaur-Sawhney, 1987). They have been shown to enhance the ability of plants to resist environmental stresses (An et al., 2004). Changes in PA biosynthesis in plant tissues have been correlated with various stresses such as $\mathrm{K}+$ deficiency, cold acclimatization, chemical stress and controlled atmospheres.

Spermidine, spermine, and their precursor putrescine are the major polyamines in plants. In its free form, polyamines exist either as putrescine (diamine putresine), spermidine (triamine spermidine) and spermine (tetraamine spermine). Putrescine is the precursor for the synthesis of spermidine and spermine (Nambeesan et al., 2008). Apart from the three well known free forms of polyamines, there are some lesser known and studied polyamines such as 1,3-diaminopropane and homospermidine which have been detected in plants (Rodriguez-Garay et al., 1989), algae (Hamana \& Matsuzuki, 1982), bacteria (Tait, 1985) and animals (Pandey et al., 2000).

At neutral (physiological) $\mathrm{pH}$ 7.0, PA are polycationic, they also occur in the free form or bound to phenolic acids. Conjugated amines have also detected in plant cells (MartinTanguy, 1997). They exist in either water soluble or forms which are insoluble in water (Pandey et al., 2000; Martin-Tanguy, 1997). While their exact roles are still uncertain, it is suggested that they act as reserve forms of amines which are released during growth at the point of synthesis or transported to other sites within plants as needed (Valero et al., 2002). In terms of the changes in polyamines in a number of crops, with few exceptions, the general trend is an increase in the concentration of free and bound polyamines especially spermine which coincides with the early stages of fruit growth at which time cell division is at its peak and a subsequent decrease at late fruit growth and the time of ripening (Valero et al., 2002). However for crops such as avocado, pear and tomato fruit (cv. Rutgers), free PA levels declined during fruit development (Saftner \& Baldi, 1990). 


\subsubsection{Biosynthesis and metabolism of the major polyamines}

The biosynthetic pathways for polyamines have been delineated for mammals, fungi, bacteria plants (Nambeesan et al., 2008; Valero et al., 2002). Polyamine biosynthesis in plants involves two pathways. Putrescine, the primary precursor and first member in the PA sequence is derived from either ornithine (direct formation) or arginine (indirect formation). If putrescine is derived from ornithine, the pathway involves the decarboxylation of ornithine in the presence of ornithine decarboxylase (ODC). When putrescine is synthesized from arginine, it is first converted to agmatine by decarboxylation of arginine decarboxylase (ADC). The enzyme arginase can convert the amino acid arginine directly to ornithine with a loss of urea. The enzyme ODC which is located in the cystol and nucleus can convert ornithine into putrescine. Ornithine can be metabolised back to arginine via the ornithine cycle. With respect to the indirect formation, the enzyme ADC, found in the cytosol, decarboxylates arginine to agmatine. The agmatine is hydrolysed to an intermediate $\mathrm{N}$ carbamoyl putrescine which then forms putrescine. Transformation of putrescine to spermidine (triamine) and spermine (tertaamine) requires stepwise transfer of aminopropyl groups from decarboxylated SAM (formed from methionine) to putrescine. The reaction is considered to be the rate-limiting step in PA biosynthesis. The PA 1,3-diaminopropane is formed by the oxidation of spermine and spermidine. Cadaverine another PA is formed via the decarboxylation of lysine (Slocom et al., 1984; Nambeesa et al., 2008).

Once formed, PA may be metabolized in various ways e.g. they can be conjugated or they can undergo oxidation. In plants, putrescine and spermidine are often bonded via their amino groups with the carboxyl groups of aromatic acids such as cinnamic and coumaric acids to form conjugates. PAs may be oxidized by a variety of enzymes in plants called amine oxidases. Diamine oxidases can convert putrescine to ammonia $\left(\mathrm{NH}_{3}\right)$, hydrogen peroxide $\left(\mathrm{H}_{2} \mathrm{O}_{2}\right)$ and delta-pyrroline. Delta-pyrroline can be ultimately converted to succinic acid. PA oxidases can oxidize spermine and spermidine to 1,3-diaminopropane (Martin-Tanguy, 1997).

Polyamines are well known for their anti-senescence properties (Panday et al., 2000) whereas ethylene is known to initiate ripening and eventual senescence. The anti-senescent activity of polyamines may also be related to their ability to be effective free radical scavengers as well as stabilizing DNA and membranes by associating with negative charges on nucleic acids and phospholipids (Droplet et al., 1986). Their role in anti-senescence is believed to be related to their positively charged cations which are able to interact with negatively charged anions of membrane. Their cationic capability as well as their antioxidant property is believed to play a role preserving membrane integrity (Roberts et al., 1986). Ethylene, spermidine and sperminine share a common precursor S-adenosyl methionine (SAM) (Nambeesan et al., 2008; Pandey et al., 2000). Since they both exert opposite effects, it has been suggested that both ethylene and polyamines compete for this common precursor SAM. SAM is a substrate for 1aminocyclopropane-1-carboxylic acid (ACC) in the synthesis of ethylene. SAM is also a substrate for SAM decarboxylase in a pathway that leads to the synthesis of PA. Thus the possibility exists that the biosynthesis of both may be closely linked (Panday et al., 2000; Saftner \& Baldi, 1990). PA have shown inhibitory effects on ethylene synthesis in a variety of plant tissues as described by Nambeesan et al. 2008. Elevated PA (putrescine) levels have been correlated with prolonged storage characteristics in tomato fruit. From a postharvest physiological and quality perspective, free polyamines that are endogenously synthesized or exogenously applied have been found to exert its anti-senescence effect on a range of 
horticultural crops (Valero et al., 2002). These effects have been shown in retardation of colour changes, enhanced mechanical resistance, reduction in chilling injury, increase in fruit firmness and delayed respiration and ethylene production. The biosynthetic pathways of ethylene, spermidine and spermine are given in Figure 3.

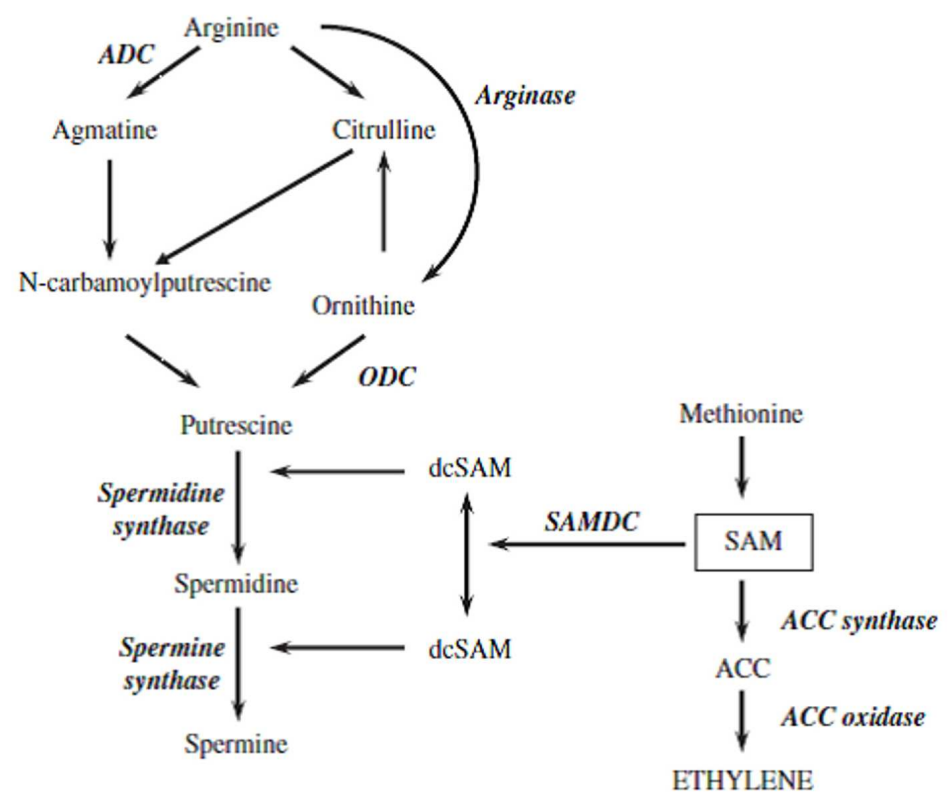

Fig. 4. Pathways (and related enzymes) of the ethylene and polyamine biosynthesis (adapted from Tassoni et al., 2006). ADC-arginine decarboxylase, ODC-ornithine decarboxylase, dcSAM-decarboxylated SAM, SAMDC-S-adenosyl methionine decaboxylase SAM- S-adenosyl methionine ACC-amino cyclopropane carboxylic acid

\subsubsection{The effect of polyamines and UV-C stress}

The intricate balance of polyamines and ethylene is suggested to play a central role in accelerating or retarding ripening and senescence (Pandey et al., 2000). A number of studies have been conducted to determine the possible effect of exogenous application of polyamines on ethylene production, senescence and other physio-chemical changes in fruit and vegetables and cut flowers. Four varieties of Japanese plums were treated with polyamines and their effects on ethylene production were measured (Serrano et al., 2003). Three varieties were typical climacteric types. In these varieties, treatment with polyamines resulted in a reduction and/or delay in the ethylene peak. One variety "Golden Japan" was known to behave in a non-climacteric fruit manner and therefore ethylene production remained low in treated and controlled fruits. Spermine and spemidine were more effective in inhibiting ethylene than putrescine in peaches when the application of polyamines to the canopy of the tree was studied (Breglio et al., 2002). In apricots, treatment with putrescine inhibited ethylene production during postharvest storage when compared to untreated fruit (Martinez-Romero et al., 2002). Application of exogenous polyamines on apple fruits 
however did not affect ethylene production when compared to untreated fruits (Wang et al., 1993). Valero et al. (2002) suggested that the difference in responses to exogenous application of ethylene production in climacteric fruits, may be explained by an understanding of the intrinsic ethylene production capacity of a particular horticultural commodity of a cultivar within a specific class of fruit. In commodities with low levels of ethylene production, treatment with polyamines result in the inhibition or delay in ethylene production while commodities with high levels of ethylene production, polyamines are not effective in delaying or inhibiting ethylene production.

However, in spite of well-documented protective role of PA in plants under damaging action of various stressors (high and low temperature, salinity, drought and others), molecular mechanisms of PA defensive effects and their biological significance in plant survival and adaptation remain obscure. Further only a few publications concerning PA oxidative degradation under the effect of UV-C irradiation have been reported. A high level of endogenous PA and plant tolerance to oxidative stress can be based not only on stressinduced but also on the constitutively high PA biosynthesis. It was reported that UV-C irradiation increased polyamine levels in the skin tissue of mango fruit. Higher levels of polyamines (putrescine and spermidine) were noted in mango fruits treated with UV-C for 10 minutes compared to controls and those irradiated for a longer period of 20 minutes (González-Aguilar et al., 2001). UV-C treated tomato fruits were firmer in texture and less red in colour indicating a delay in ripening (Liu et al., 1993). Similar results were noted in tomato fruit colour in addition, there was a delay in the appearance of the climacteric phase in irradiated fruit as well as reduced rates of $\mathrm{CO}_{2}$ and $\mathrm{C}_{2} \mathrm{H}_{4}$ when compared to the controls. Further, optimal doses of UV-C produced higher levels of free and conjugated polyamines, particularly putrescine when compared to the control in tomato fruits during storage at $16^{\circ} \mathrm{C}$ (Maharaj et al., 1999). It has been reported that polyamines are not directly associated with a delay in tomato fruit ripening, but may prolong the fully-ripe stage before the fruit tissues undergo senescence (Tassoni et al., 2006). Thus the anti-senescent activity of polyamines may be related to their effectiveness as free radical scavengers more so than exerting opposite physiological effect to ethylene. Table 1 illustrates the increase in free PA in tomato pericarp subjected to UV-C hormic dose. In another study, UV-treated tomato during the first 5 days after irradiation, exhibited a significant induction of lipid peroxidation markers, suggesting that cell membrane was the primary target of UV-C irradiation. The levels then dropped lower than in control fruits suggesting the induction of a defence or repair mechanism. Treated fruits exhibited significantly less cell wall degrading enzymes (CWDE) activity compared to controls (Barka, et al., 2000a, 2000b).

\begin{tabular}{|c|c|c|c|}
\hline \multirow{2}{*}{ Storage Time (days) } & \multicolumn{3}{|c|}{ Free Putrescine in Tomato Pericarp (nmoles/g fw) } \\
\hline 0 & Control & UV-3.7 Merg/cm ${ }^{2}$ & UV-24.4 Merg/cm² \\
\hline 7 & 123.8 & 125.0 & 120.0 \\
\hline 14 & 306.7 & 418.1 & 386.4 \\
\hline 21 & 374.5 & 513.0 & 400.7 \\
\hline SEM-Pooled & 39.0 & 452.0 & 292.8 \\
\hline
\end{tabular}

Table 1. Effect of UV-C radiation on free putrescine levels in tomato pericarp during storage at $16^{\circ} \mathrm{C} .(\mathrm{n}=3)$. 


\section{Conclusion}

One of the primary objectives of postharvest interventions is to maintain the quality and safety of horticultural products along the value chain. Fruits and vegetables undergo a series of physiological changes from the point of harvest to final consumption. These processes eventually lead to senescence and ultimately death of the tissue. Over the last few decades, attention has shifted from quality maintenance of harvested crops to enhancement of healthpromoting properties of phytochemicals. This has also shifted focus in developing technologies that may enhance shelf life and preserve the availability of such phytochemicals for the benefit of consumers. Non-ionizing, artifical, germicidial UV-C radiation is one such emerging technology. The role of UV-C hormesis (stimulation of beneficial responses by low levels of stressors which otherwise cause harmful responses) in altering the biotic relationship of higher plants as shown by changes in plant disease susceptibility, production of anti-fungal compounds, its relationship to polyamines, antioxidants and phenols will no doubt be a continued area of active research. This technology appears to be promising in the food and agriculture sector in order to minimize postharvest losses of horticultural crops by delaying ripening and senescence and controlling the incidence of decay which is also a significant and important development. In fact there is a view that UV-C is at the crossroads from laboratory research to commercial applications.

\section{References}

Adhami, V.M.; Syed, D.N.; Khan, N. \& Afaq, F. (2008). Phytochemicals for prevention of solar ultraviolet radiation-induced damages. Phytochemistry and Photobiology, Vol.84, pp. 489-500.

Allende, A.; McEvoy, J.L.; Luo, Y.; Artes, F. \& Wang, C.Y. (2006). Effectiveness of two-sided UV-C treatments in inhibiting natural microflora and extending the shelf-life of minimally processed "Red Oak Leaf" lettuce. Food Microbiology, Vol.23, No.3, (May 2006), pp. 241-249.

Allende, A.; Tomás-Barberán, F.A. \& Gil, M.I. (2006). Minimal processing of healthy foods. Trends in Food Science and Technology, Vol.17, pp: 513-519.

Alothman, M.; Bhat, R. \& Karim, A.A. (2009). UV-radiation-induced changes of antioxidant capacity of fresh-cut tropical fruits. Innovative Food Science and Emerging Technologies, Vol.10, No.4, pp. 512-516.

An I.N.; Liu G.X.; Zhang M.X.; Chen T.; Lin Y.H.; Feng H.Y.; Xu S.J.; Qiang, W.Y. \& Wang, X.L. (2004). Effect of enhanced UV-B radiation on polyamine content and membrane permeability in cucumber leaves. Russian Journal of Plant Physiology, Vol. 51, No.5, pp. 658-662.

Anderson, J.G., Rowan, N.J., MacGregor, S.J., Fouracre, R.A. \& Farish, O. (2000). Inactivation of food-borne enteropathogenic bacteria and spoilage fungi using pulsed-light. IEEE Trans. Plasma Sci. Vol.28, pp. 83-88.

Anderson Artes-Hernandez, F.; Escalona, VH.; Robles, PA.; Martinez-Hernandez, G.B. \& Artes, F. (2009). Effect of UV-C radiation on quality of minimally processed spinach leaves. J Sci Food Agric, Vol. 89, pp. 414-21.

Arul, J.; Mercier, J.; Charles, M.T.; Baka, M. \& Maharaj, R. (2001). Phytochemical treatment for control of post-harvest diseases in horticulture crops. In: Physical Control Methods in Plant Protection, C. Vincent, B. Panneton \& F. Fleurat-Lessard (Eds.), pp. 146-161 INRA editions, Paris. 
Barka, E.A.; Kalantari, S.; Makhlouf, J. \& Arul, J. (2000a). Effects of UV-C irradiation on lipid peroxidation markers during ripening of tomato (Lycopersicon esculentum L.) fruits. Australian Journal of Plant Physiology, Vol.27, pp. 147-152.

Barka, E.A.; Kalantari, S.; Makhlouf, J. \& Arul, J. (2000b). Impact of UV-C irradiation on the cell wall-degrading enzymes during ripening of tomato (Lycopersicon esculentum L.) fruit. Journal of Agricultural and Food Chemistry, Vol.48, pp. 667-671.

Bintsis, T.; Litopoulou-Tzanetaki, E. \& Robinson R.K. (2000). Existing and potential application of ultraviolet light in the food industry - a critical review. Journal of the Science of Food and Agriculture, Vol.90, pp. 637-645.

Brady, C.J. (1987). Fruit Ripening. Annual Review of Plant Physiology, Vol.38, pp. 155-178.

Bregoli, A.M.; Scaramaglis, Costa G.; Sabatini, E.; Ziosi, V.; Stefania. B. \& Torrigiani, T. (2002). Peach (Prunus persica) fruit ripening aminoethoxyvinyl glycine (AVG) and exogenous polyamines affect etlylene emission and flesh firmness Physiologia Plantarum, Vol.114, pp. $472-481$.

Butt, M.S. \& Sultan, M.T. (2011). Nutritional profile of vegetables and its significance to human health. In: Handbook of Vegetables and Vegetable processing N.K. Sinha (Ed.) pp.107-123 ISBN 978-0-8138-1541-1. Blackwell Publishing Ltd Ames Iowa.

Calabrese, M.M.; McCarthy.; M.E. \& Kenyon, E. (1987). The occurrence of chemically induced hormesis. Health Physics, Vol. 52, pp. 531-541.

Caldwell, M.M. (1981). Plant response to solar ultraviolet radiation, In: Physiological Plant Ecology 1-Responses to the Physical Environment. O.L. Lange.;P.S. Nobel.; C.B. Osmond \& H. Ziegler, (Eds.), Chpt 6, Springer-Verlac, ISBN, Berlin, Heidelberg.

Charles, M.T.; Tano, K.; Asselin, A. \& Arul J. (2009). Physiological basis of UV-C induced resistance to Botrytis cinerea in tomato fruit. V. Constitutive defence enzymes and inducible pathogenesis related proteins. Postharvest Biology and Technology, Vol. 51, pp. 414-24.

Costa. L.; Vincente A.R.; Civello P.M.; Chaves A.R. \& Martinez G.A. (2006). UV-C treatment delays postharvest senescence in broccoli floret. Postharvest Biology and Technology, Vol. 39, No. 2, pp. 204-210.

Cunningham, M.L.; Johnson, J.S.; Giovanazzi, S.M. \& Peak, M.J. (1985). Photosensitized production of superoxide anion by monochromatic (290-405 $\mathrm{nm})$ ultraviolet radiation of NADH and NADPH coenzymes. Photochemistry and Photobiology, Vol. 42, No.2, pp. 125-128.

Droplet, G.; Dumbroff, E.B.; Legge, R.L. \& Thompson J.E. (1986). Radical scavenging of polyamines. Phytochemistry, Vol.25, pp. 367-37.

El Ghaouth, A.; Wilson, C.L. \& Callahan, A.M. (2003). Induction of chitinase, beta-1,3glucanase, and phenylalanine ammonia-lyase in peach fruit by UV-C treatment. Phytopathology, Vol.93, pp. 349-55.

Elmnasser, N.; Guillou, S.; Leroi, F.; Orange, N.; Bakhrouf, A. \& Federighi, M. (2007). Pulsedlight system as a novel food decontamination technology: a review. Canadian Journal of Microbiology, Vol.53, No.7, pp.813-821.

FAO, (2009). Fruits and Vegetables: An Overview on Socio-Economical and Technical Issues, In: Handling and preservation of fruits and vegetables by combined methods for rural areas. Chapter 1, FAO Agricultural Services Bulletin 149. http://www.fao.org/DOCREP/005/Y4358E/y4358e04.htm

Galston, A.W. \& Sawhney, R.K. (1987). Polyamines as indigenous growth regulators. In: Plant Hormones and Their Role in Plant Growth and Development 2nd Edition . P.J Davies (Eds.), Dordrecht: Kluwer Academic Press, pp. 155-178. 
Galston, A.W. \& Sawhney, R.K. (1990). Polyamines in plant physiology. Plant Physiology Vol.94, pp. $406-410$.

Gong, Y. \& Mattheis, J.P. (2003). Effect of ethylene and 1-methyl-cyclopropane on chlorophyll catabolism of broccoli florets. Plant Growth Regulation, Vol. 40, pp. 33-38.

Gómez-López, V.M.; Devlieghere, F.; Bonduelle, V. \& Debevere, J. (2005). Factors affecting the inactivation of micro-organisms by intense light pulses. Journal of Applied Microbiology, Vol.99, No.3, pp. 460-470.

González-Aguilar, G.A.; Wang, C.Y.; Buta, J.G. \& Krizek, D.T. (2001). Use of UV-C irradiation to prevent decay and maintain postharvest quality of ripe "Tommy Atkins" mangoes. International Journal of Food Science, Vol.36, pp. 767-773.

González -Aguilar, G.A.; Villega-Ochroa M.A.; Martinez-Telez M.A.; Gardea A.A. \& Ayala Zavala J.F. (2007). Improving antioxidant capacity of fresh cut mangoes treated with UV- C. Journal of Food Science, Vol.36, pp. S197-S202.

Hamana, K. \& Matsuzaki, S. (1982). Widespread occurance of non spermidine and non spermine in eukargolic algae Journal of Biochemistry, Vol.91, pp. 1321-1324.

Heby, O. \& Persson, L. (1990). Motecular genetics of polyamine synthesis in eukaryotic cells. Trends in Biochemical Science, Vol.15, pp. $153-158$.

Heber, D. (2004) Vegetables, fruits and phytoestorogen in prevention of diseases. Journal of Postgraduate Medicine, Vol.50, pp. 145-149.

Hemmaty, S.; Moallemi, N. \& Naseri, L. (2006). Shelf-life and quality of apple fruits in response to postharvest application of UV-C radiation. Journal of Applied Horticulture,Vol.8, No.2, (July-December 2006), pp. 114-116.

Jaleel, C.A.; Riadh, K.; Gopi, R.; Manivannan, P.; Inès, J.; Al-Juburi, H.J.; Hong-Bo, Z.S. \& Panneerselvam, R. (2009). Antioxidant defence responses: physiological plasticity in higher plants under abiotic constraints. Acta Physiol Plant, Vol.31, pp. 427-436.

Jiang,T.; Jahangir, M.M.; Jiang, Z. \& Lu, X. (2010). Influence of UV-C treatment on antioxidant capacity, antioxidant enzyme activity and texture on postharvest Shitake (Lentinus edodes) mushrooms during storage. Postharvest Biology and Technology, Vol.56, No.3, pp. 209-215.

Kataoka, I.; Sugiyama, A. \& Beppu, K. (2003). Role of ultraviolet radiation in accumulation of anthocyanin in berries of 'Gros Colman' grapes (Vitis vinifera L.). Journal of the Japenese Society for Horticulture Science, Vol.72, pp. 1-6.

Katerova, Z. (2009). Prolonged influence of short pulses ultraviolet-C radiation on young pea plant does not alter important antioxidant defence enzyme activities in young leaves. General and Applied Plant Physiology, Vol.35, No.3-4, pp. 134-139.

Kowalski, W. (2009). Ultraviolet Germicidal Irradiation Handbook, Springer-Verlag, Berlin Heidelberg pp.1-493.

Langcake, P. \& Pryce, R. (1973). The production of resveratrol and viniferins by grapevines in response to ultraviolet irradiation. Phytochemistry, Vol.16, pp. 1193-1196.

Li, J.; Zhang, Q.; Cui, Y.; Cao, J.; Zhao, Y. \& Jiang, W. (2010). Use of UV-C treatment to inhibit microbial growth and maintain the quality of Yali pear. Journal of Food Science, Vol.75, No.7, pp. M503-M507.

Liu, J.; Stevens, C.; Khan, V. A.; Lu, J. Y.; Wilson, C. L.; Adeyeye, O.; Kabwe, M.K; Pusey, P.L.; Chalutz, E.; Sultana, T. \& Droby, S. (1993). Application of ultraviolet-C light on storage rots and ripening of tomatoes. Journal of Food Protection, Vol.56, (October 1993), pp. 868- 872.

Liu, L.H.; Zabaras, D.; Bennett, L.E.; Aguas, P. \& Woonton, B.W. (2009). Effects of UV-C, red light and sun light on the carotenoid content and physical qualities of tomatoes during post-harvest storage. Food Chemistry, Vol.115, pp. 495-500. 
Maharaj, R.; Arul, J. \& Nadeau, P. (1999). Effect of photochemical treatment in the preservation of fresh tomato (Lycopersicon esculentum cv. Capello) by delaying senescence. Postharvest Biology and Technology, Vol.15, No.1, pp. 13-23.

Maharaj, R.; Arul, J. \& Nadeau, P. (2010). UV-C Irradiation of Tomato and its Effects on Colour and Pigments. Advances in Environmental Biology, Vol.4, No.2, pp. 308-315, ISSN 19950756 .

Marquenie, D.; Michiels, C.W.; Geeraerd, A.H.; Schenk, A.; Soontjens, C.; Van Impe, J.F. \& Nicolar", B.M. (2002). Using survival analysis to investigate the effect of UV-C and heat treatment on storage rot of strawberry and sweet cherry. International Journal of Food Microbioogy, Vol.73, pp. 191-200.

Martinez-Romero, D.; Serrano, M.; Carbonell, A.; Burgos L.; Riquelme, F. \& Valero, D. (2002). Effects of post harvest putrescine treatment on extending shelf life and reducing mechanical damage in apricot. Journal of Food Science, Vol.67, No.5, pp. 1706 - 1712.

Martin-Tanguy, J. (1997). Conjugated polyamines and reproductive development: biochemical, molecular and physiological approaches. Physiologia Plantarum, Vol. 100, pp. 675-688.

Mercier, J.; Baka, M.; Reddy, B.; Corcuff, R. \& Arul, J. (2001). Shortwave ultraviolet irradiation for control of decay caused by Botrytis cinerea in bell pepper: Induced resistance and germicidal effects. J Am Soc Hort Sci, Vol.126, pp. 128-33.

Nambeesam, S.; Handa, A.K. \& Maltoo, A.K. (2008). Polyamines and regulation of ripening and senescence In : Postharvest Biology and Technology of fruits, vegetables and flower seeds. G. Paliyath, D.P Murr, A.K Handa and S.Larie.(Eds.) ISBN 978-0-8138-0408-8 Wiley, Black Well , Iowa U.S.A.

Nigro, F.; Ippolito, A. \& Lima, G. (1998). Use of UV-C light to reduce Botrytis storage rot of table grapes. Postharvest Biology and Technology, Vol.13, pp. 171-181.

Nigro, F.; Ippolito, A.; Lattanzio, V.; Di Venere, D. \& Salerno, M. (2000). Effect of ultraviolet-C light on postharvest decay of strawberry. Journal of Plant Pathology, Vol.82, No.1, pp. 29-37.

Pandey, S.; Ranade, S.A.; Nagar, P. K. \& Kumar, N. (2000). Role of Polyamines and Ethylene as Modulators of plant senescene. Journal of Bioscience, Vol.25, No.3, pp. 291 - 298.

Pearce, R.S. (1999). Molecular analysis of acclimation to cold. Plant Growth Regulation, Vol. 29, pp. 47-76.

Ramana-Luximon, A.; Behorun, T. \& Crozier, A. ( 2003). Antioxidant actions and phenolic and Vitamin C content of common Mauritian exotic fruits. Journal of the Science of Food and Agriculture, Vol.83, pp. 496-502.

Rame, J.; Chaloupecky, V.; Sojkova, N. \& Bencko, V. (1997). An attempt to demonstrate the increased resistance of selected bacterial strains during repeated exposure to UVradiation at $254 \mathrm{~nm}$. Central European Journal of Public Health, Vol.4, pp. 30-31.

Roberts, D.R.; Dumdroff, E.B. \& Thompson, J.E. (1986) Exogenous polyamines alter membrane fluidity - a potentail for misinterpretation of their physiological role Planta, Vol.167, pp. 395-401

Rodriguez-Garay, B.; Phillip, G.C. \& Kuehn, G.D. (1989). Defection of norspermine in Medicago sativa L.(alfalfa). Plant Physiology, Vol.89, pp. 525-529.

Saftner, R.A. \& Baldi, G.B. (1990). Polyamine levels and tomato fruit development possible interaction With Ethylene. Plant Physiology, Vol.92, No.2, pp. 547-550.

Schreiner, M. \& Huyskens-Keil, S. 2006. Phytochemicals in fruit and vegetables: health promotion and postharvest elicitors, In: Red Orbit, 20.06.06, Available from http://www.redorbit.com/news/science/543640/phytochemicals_in_fruit_and_veg etables_health_promotion_and_postharvest_elicitors 
Serrano, M.; Martinez-Romero, D.; Guillen, F. \& Valero, D. (2003). Effects of exogenous putrescine on improving shelf life of four plum cultivars. Postharvest Biology and Technology, Vol.30, pp. 259-271.

Shahidi, F.; Chandrasekara, A. \& Zhong ,Y. (2011). Bioactive phytochemicals in vegetables In: Handbook of Vegatables and Vegetable processing. N.K Sinha (Ed), pp. 125-158. Blackwell publishing Ltd. Ames Iowa.

Shahidi, F. \& Naczk, M. (2004). Phenolics in Food and Neutraceuticals, pp. 1-82. CRC Press Boca Raton

Shama, G. (2007). Process challenges in applying low doses of ultra violet light to fresh produce for eliciting beneficial hermetic responses. Postharvest Biology and Technology, Vol.44, No.1, pp. 1-8.

Shama, G. \& Alderson, P. (2005). UV hormesis in fruits: a concept ripe for commercialization. Trends in Food Science and Technology, Vol.16, pp. 128-136.

Slocum, R.D.; Kaur-Sawhney, R. \& Galston, A.W. 1984. The physiology and biochemistry of polyamines in plants. Archives of Biochemistry and Biophysics, Vol.235, pp. 283-303.

Stapleton, A.E. (1992). Ultraviolet radiation and plants: burning questions. The Plant Cell, Vol.4, (November 1992), pp. 1353-1358.

Stevens, C.; Khan, Y.A.; Tang, A.Y. \& Lu, Y.J. (1990). The effect of ultraviolet radiation on mold rots and nutrients of stored sweet potatoes. Journal of Food Protection, Vol.53, No.3, pp. 223-226.

Stevens, C.; Wilson, C.L.; Lu, Y.J.; Khan, V.A.; Chalutz, E.; Droby, S.; Kabwe, M.K; Haung, Z.; Wisniewski, M.E.; Adeyeye, O.; Pusey, L.P. \& West, M. (1996). Plant hormesis induced by ultraviolet light-C for controlling postharvest diseases of tree fruits. Crop Protection, Vol.15, pp. 129-134.

Tait, G.H. (1985). Bacterial Polyamines, structure and biosynthesis: Biochemical Society Transactions, Vol.13, pp. $316-318$.

Tassoni, A.; Watkins, C.B. \& Davies, P.J. (2006). Inhibition of the ethylene response by 1-MCP in tomato suggest that polyamines are not involved in delaying ripening, but may moderate the rate of ripening or over-ripening. Journal of Experimental Botany, Vol.57, No.12, pp. 3313-3325.

Tomás-Barberán, F.A. \& Espín, J.C. (2001). Phenolic compounds and related enzymes as determinants of quality in fruits and vegetables. Journal of the Science of Food and Agriculture, Vol.81, pp. 853-876.

Valero, D.; Romero, D.M. \& Serrano, M. (2002). The role of polyamines in the improvement of shelf life of fruit. Trends in Food Science and Technology, Vol.13, pp. 228 - 234.

Vikhanski, L. (1989). Environmental Watch. Discoverer, Vol.9, pp 32.

Wang, C.Y.; Conway, W.S.; Abbott, J.A. \& Kramer, G.F. (1993). Post harvest infiltration of polyamines and calcium influences ethylene production and technology changes in golden delicious apples. Journal of the American Society of Horticultural Science, Vol.188, No. 6, pp. $801-806$.

Wills, R.B.H.; McGlasson, W.D.; Graham, D.; Lee, T.H. \& Hall, E.C. (1981). Postharvest: An Introduction to the Physiology and Handling of Fruits and Vegetables, AVI Van Nostrand, ISBN, 9780870554025, New York.

Yahia, E. (1998). Modified and controlled atmospheres for tropical fruits. Horticultural Reviews, Vol. 22, pp. 123-183. 


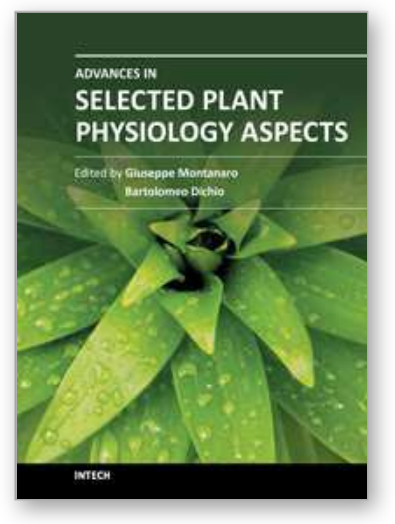

\author{
Advances in Selected Plant Physiology Aspects \\ Edited by Dr. Giuseppe Montanaro
}

ISBN 978-953-51-0557-2

Hard cover, 388 pages

Publisher InTech

Published online 25, April, 2012

Published in print edition April, 2012

The book provides general principles and new insights of some plant physiology aspects covering abiotic stress, plant water relations, mineral nutrition and reproduction. Plant response to reduced water availability and other abiotic stress (e.g. metals) have been analysed through changes in water absorption and transport mechanisms, as well as by molecular and genetic approach. A relatively new aspects of fruit nutrition are presented in order to provide the basis for the improvement of some fruit quality traits. The involvement of hormones, nutritional and proteomic plant profiles together with some structure/function of sexual components have also been addressed. Written by leading scientists from around the world it may serve as source of methods, theories, ideas and tools for students, researchers and experts in that areas of plant physiology.

\title{
How to reference
}

In order to correctly reference this scholarly work, feel free to copy and paste the following:

Maharaj Rohanie and Mohammed Ayoub (2012). Significance of UV-C Hormesis and Its Relation to Some Phytochemicals in Ripening and Senescence Process, Advances in Selected Plant Physiology Aspects, Dr. Giuseppe Montanaro (Ed.), ISBN: 978-953-51-0557-2, InTech, Available from: http://www.intechopen.com/books/advances-in-selected-plant-physiology-aspects/significance-of-uv-chormesis-and-its-relation-to-some-phytochemicals-in-ripening-and-senescence-pro

\section{INTECH}

open science | open minds

\author{
InTech Europe \\ University Campus STeP Ri \\ Slavka Krautzeka 83/A \\ 51000 Rijeka, Croatia \\ Phone: +385 (51) 770447 \\ Fax: +385 (51) 686166 \\ www.intechopen.com
}

\author{
InTech China \\ Unit 405, Office Block, Hotel Equatorial Shanghai \\ No.65, Yan An Road (West), Shanghai, 200040, China \\ 中国上海市延安西路65号上海国际贵都大饭店办公楼 405 单元 \\ Phone: +86-21-62489820 \\ Fax: +86-21-62489821
}


(C) 2012 The Author(s). Licensee IntechOpen. This is an open access article distributed under the terms of the Creative Commons Attribution 3.0 License, which permits unrestricted use, distribution, and reproduction in any medium, provided the original work is properly cited. 